\title{
Synthesis and Characterization of New Photoluminescent Oxadiazole/Carbazole-Containing Polymers
}

\author{
Simona Concilio, ${ }^{1}$ Valeria Bugatti, ${ }^{1}$ Pio Iannelli, ${ }^{2}$ and Stefano Piotto Piotto ${ }^{2}$ \\ ${ }^{1}$ Department of Chemical and Food Engineering, University of Salerno, Via Ponte Don Melillo, 84084 Fisciano, Italy \\ ${ }^{2}$ Department of Pharmaceutical Science, University of Salerno, Via Ponte Don Melillo, 84084 Fisciano, Italy
}

Correspondence should be addressed to Simona Concilio, sconcilio@unisa.it

Received 5 November 2009; Accepted 14 March 2010

Academic Editor: Jinying Yuan

Copyright (C) 2010 Simona Concilio et al. This is an open access article distributed under the Creative Commons Attribution License, which permits unrestricted use, distribution, and reproduction in any medium, provided the original work is properly cited.

\begin{abstract}
We report on the synthesis and the characterization of a new class of segmented polyethers POC containing the oxadiazole and carbazole units. The polymers exhibit a high thermal stability, high glass transition temperatures, and good solubility in common organic solvents, despite the extended aromatic portion in the main polymer chain. The synthetic procedures are simple, and no acid side-products are obtained. According to previous reports on oxadiazole/carbazole-containing materials, POCs show high photoluminescence activity in the blue region of the visible spectra. The good solubility in chlorinate solvents allows the preparation of films with homogeneous thickness by spin coating. Glass transition temperature in the range $115-125^{\circ} \mathrm{C}$ ensures good stability of film morphology at room temperature. The only exception is $\mathrm{POC}(6)$, which shows a poor solubility and higher $T_{g}\left(170^{\circ} \mathrm{C}\right)$, due to its shorter aliphatic chain portion. For these features, polymers POC are potential candidate materials for fabricating blue light-emitting devices.
\end{abstract}

\section{Introduction}

Phosphorescent polymer light-emitting diodes (PLEDs) have attracted considerable attention for their convenient preparation from solution by spin coating or inkjet printing methods. In order to have a balanced carrier recombination in the emitting layer, the polymer should possess good carrier transport properties, as well as energy level matching with electrodes for effective charge injection [1-13].

To improve the electron transfer in PLEDs, researchers usually spin a p-type polymer on an n-type polymer with electron transport properties. But this kind of multilayer system may suffer difficulties in spinning a polymer solution on an organic film, which can easily dissolve. To deal with this issue, polymers containing both hole- and electrontransporting moieties have been prepared. Recently, polymers with either electron-withdrawing (such as oxadiazole, diphenylquinoline, etc.) or electron-donating groups (such as triphenylamine, carbazole, etc.) have been prepared [1417].

Oxadiazole/carbazole derivatives having good solubility, high quality film formation, and a strong blue emission can play a very important role in organic/polymeric optoelectronic materials, and they can be used as single-layer materials for OLEDs.

In this work we report on the synthesis and characterization of a series of oxadiazole/carbazole-containing polymers (POCs), having the formula mentioned in Scheme 1, where $n$ is 12 or 6 for the two homopolymers and 12 and 6 or 8 and 4 for the two copolymers. The synthetic procedures are based on the Williamson condensation reaction. All the polymers show high glass transition temperatures and good solubility in common organic solvents. According to previous reports on oxadiazole/carbazole-containing materials [18], POCs show high photoluminescence activity in the blue region of the visible spectrum. Compared to the low-molecular-weight compounds, the new polymers show higher thermal stability and the possibility to be processed in high-quality thin films by solution casting or spin coating.

\section{Experimental}

2.1. Materials. All reagents and solvents were purchased from Aldrich and Carlo Erba. N,N-dimethylacetamide 


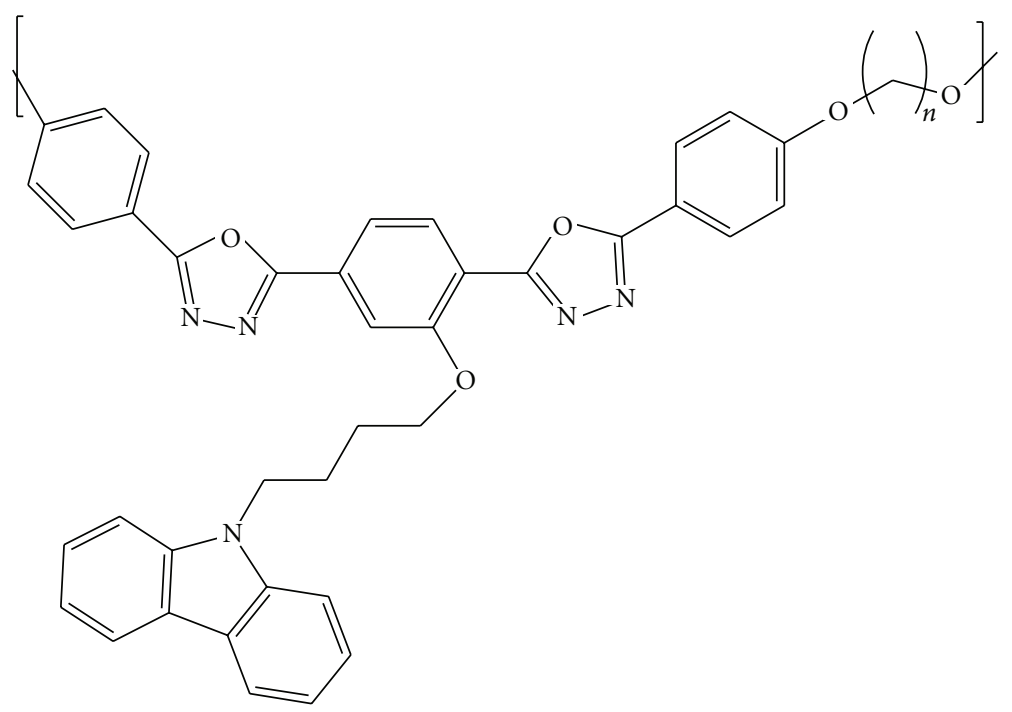

SCHEMe 1

(DMAc) and N,N-dimethylformamide (DMF) were refluxed on calcium hydride, distilled in vacuum, and stored on $4 \AA$ molecular sieves. Other reagents were used without further purification. 2-(4-carbazol-9-yl-butoxy)-terephthalic acid dihydrazide was synthesized according to a previously reported procedure [18].

\subsection{Synthesis of the Monomer}

2.2.1. Synthesis of Compound 1. To a suspension of compound 2-(4-carbazol-9-yl-butoxy)-terephthalic acid dihydrazide $(0.00460 \mathrm{~mol}, 2.00 \mathrm{~g})$ in dry DMAc $(50 \mathrm{~mL})$ at room temperature, the 4-acetoxybenzylchloride $(0.0101 \mathrm{~mol}, 2: 1$ $+10 \%)$ was added and the reaction was left to take place overnight under stirring. The reaction mixture was then poured into cold water $(600 \mathrm{~mL})$ and the resulting solid product was filtered, washed twice with water, and dried under vacuum. m.p. $=256^{\circ} \mathrm{C}$. The product was used in the subsequent intramolecular ring closure reaction. The proton resonance data are in agreement with the expected values.

2.2.2. Synthesis of Compound 2 . The freshly synthesized azide $1(1.0 \mathrm{~g})$ was poured in $80 \mathrm{~mL}$ of phosphorous oxychloride $\left(\mathrm{POCl}_{3}\right)$; the reaction was conducted at refluxing temperature for 5 hours. The mixture was then slowly dropped into ice water $(600 \mathrm{~mL})$, and a precipitate was collected. The crude product was then hydrolyzed with $500 \mathrm{~mL}$ of aqueous $\mathrm{KOH}$ ( $\mathrm{pH}=12-14)$, under stirring at $50^{\circ} \mathrm{C}$. The clear solution was finally neutralized to $\mathrm{pH}=7$, and the final product (compound 2, Scheme 2) was purified by crystallization from DMF/water to obtain pale yellow crystals, with m.p. = $350^{\circ} \mathrm{C}$. The proton resonance data are in agreement with the expected values: ${ }^{1} \mathrm{H}$ NMR (DMSO): $\delta(\mathrm{ppm})=8.16-8.07(\mathrm{~m}$, $3 \mathrm{H}), 7.98(d, J=8.4 \mathrm{~Hz}, 2 \mathrm{H}), 7.89-7.78(\mathrm{~m}, 4 \mathrm{H}), 7.52(d, J=$ $8.1 \mathrm{~Hz}, 2 \mathrm{H}), 7.30(t, J=7.5 \mathrm{~Hz}, 2 \mathrm{H}), 7.11(t, J=7.5 \mathrm{~Hz}, 2 \mathrm{H})$, 6.98-6.93 (m, 4H), $4.44(\mathrm{bt}, 2 \mathrm{H}), 4.28(\mathrm{bt}, 2 \mathrm{H}), 2.03(\mathrm{~m}, 2 \mathrm{H})$, $1.88(\mathrm{~m}, 2 \mathrm{H})$.
2.3. General Procedure for the Syntheses of Polymers POC (Scheme 3). To a suspension of monomer $2(0.000897 \mathrm{~mol}$, $0.570 \mathrm{~g})$, in dry DMF $(12 \mathrm{~mL})$ at $70^{\circ} \mathrm{C}$, and potassium carbonate $(0.00429 \mathrm{~mol}, 4: 1+20 \%)$, the appropriate $1, \mathrm{n}$ dibromoalkane $(0.000449 \mathrm{~mol})$, in DMF solution, was added drop-wise, and the mixture was left to reflux overnight under stirring. The reaction mixture was then poured into water $(200 \mathrm{~mL})$ and the resulting solid product was filtered and washed twice with water. The crude polymer was then collected and dried under vacuum. It was easily soluble in Chloroform, DMF, and DMSO. The proton resonance data are in agreement with the expected values.

For example, for $\operatorname{POC}(12,6):{ }^{1} \mathrm{H} \mathrm{NMR}\left(\mathrm{CDCl}_{3}\right): \delta(\mathrm{ppm})$ $=8.12-7.98(\mathrm{~m}, 6 \mathrm{H}), 7.74-7.67(\mathrm{~m}, 2 \mathrm{H}), 7.36(\mathrm{~m}, 5 \mathrm{H}), 7.22$ $(\mathrm{m}, 2 \mathrm{H}), 7.01-6.90(\mathrm{~m}, 4 \mathrm{H}), 4.40(\mathrm{~m}, 2 \mathrm{H}), 4.22(\mathrm{~m}, 2 \mathrm{H})$, $4.02(\mathrm{~m}, 4 \mathrm{H}), 2.22(\mathrm{~m}, 2 \mathrm{H}), 1.98-1.82(\mathrm{~m}, 6 \mathrm{H}), 1.62-1.32$ $(\mathrm{m}, 10 \mathrm{H})$. The spectrum is reported in Figure 1.

For the other polymers of the series, the spectra are similar, the difference is only in integration of the signals for the $-\mathrm{CH}_{2}-$ aliphatic group in the interval $(1.62-1.32) \mathrm{ppm}$.

2.4. Characterization. Thermal measurements were performed by a DSC-7 Perkin Elmer calorimeter under nitrogen flow at $10^{\circ} \mathrm{C} / \mathrm{min}$ rate.

Thermogravimetric analysis was performed with a TA Instruments SDT 2960 apparatus, in air at $20^{\circ} \mathrm{C} / \mathrm{min}$.

$\mathrm{X}$-ray diffraction spectra were recorded using a flat camera with a sample-to-film distance of $90.0 \mathrm{~mm}$ (uni-filtered $\mathrm{Cu} \mathrm{K}{ }_{\alpha}$ radiation). The Fujifilm MS 2025 imaging plate and a Fuji Bio-imaging Analyzer System, mod. BAS-1800, were used for recording and digitizing the diffraction patterns.

${ }^{1} \mathrm{H}$ NMR spectra were recorded with a Brucker DRX/400 Spectrometer. Chemical shifts are reported relative to the residual solvent peak.

UV-Vis measurements were performed by a Perkin Elmer Lambda 800 Spectrophotometer and photoluminescence was recorded by a Jasco FP-750 Spectrofluorometer. 


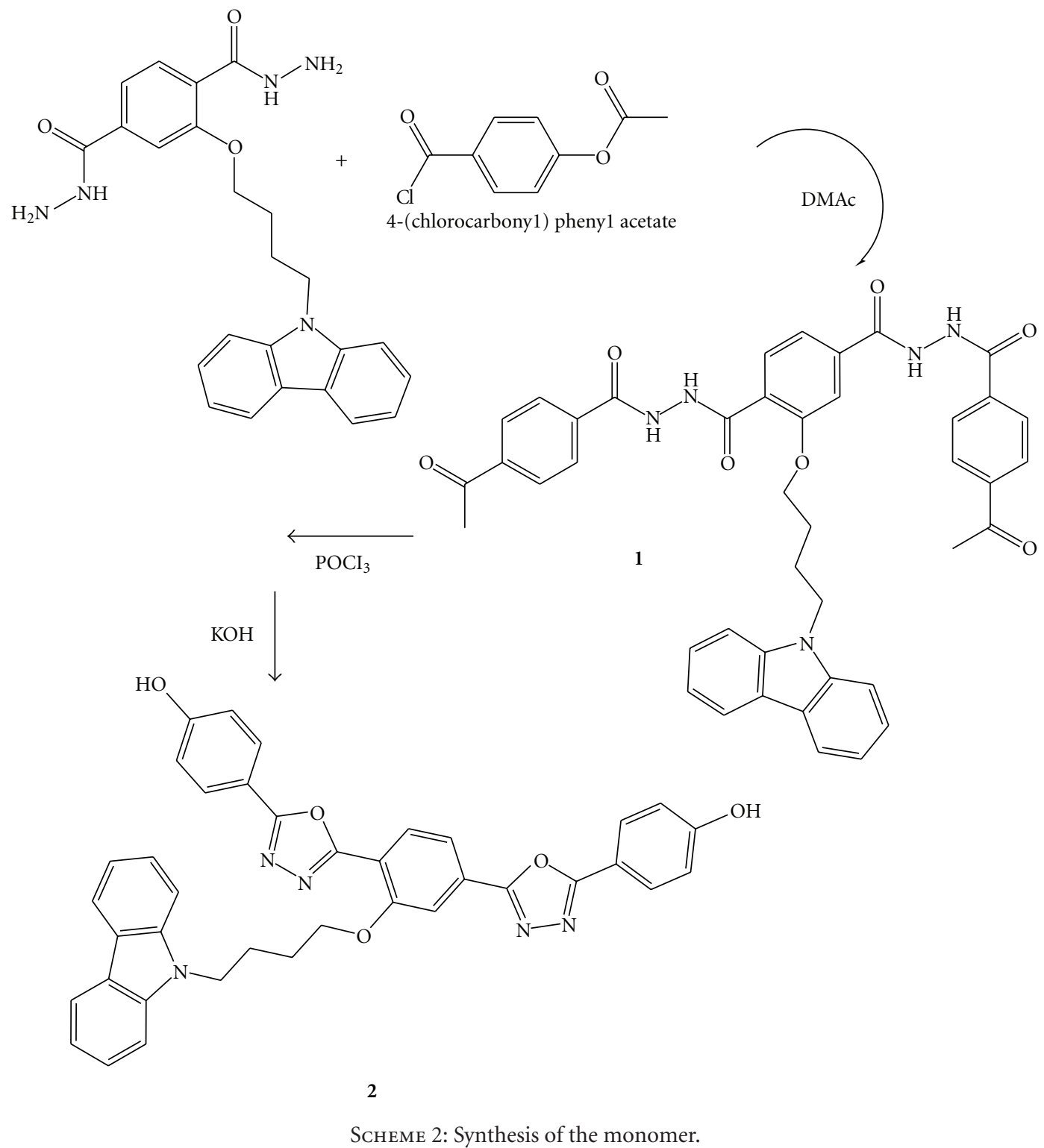

\section{Results and Discussion}

3.1. Structural and Calorimetric Characterization. The structure of all polymers POC was confirmed by proton NMR analysis. The NMR spectrum of $\operatorname{POC}(12,6)$ in deuterated chloroform solution is reported in Figure 1 as a representative example.

Thermodynamic data of POC are listed in Table 1. From the DSC analysis only the glass transition temperature is observed, which indicates that POCs, as obtained from the synthesis, are amorphous polymers, with glass transition temperatures depending on the length of aliphatic segments in the main chain. As expected, shorter aliphatic chains lead to higher $T_{g}$ while intermediate values are observed for the copolymers with mixed length of chains.

Glass transition temperature in the range $115-125^{\circ} \mathrm{C}$ ensures good stability of film morphology at room temperature. The only exception is $\operatorname{POC}(6)$, which shows a poor
TABle 1: Features of POC $(n, m)$.

\begin{tabular}{lccc}
\hline Polymer & $T_{g}\left({ }^{\circ} \mathrm{C}\right)^{*}$ & $T_{d}\left({ }^{\circ} \mathrm{C}\right)^{* *}$ & Solvent*** \\
\hline POC $(12)$ & 122 & 314 & $\mathrm{CHCl}_{3}$ \\
POC $(6)$ & 169 & 359 & $\mathrm{DMF}^{*}$ \\
POC $(12,6)$ & 115 & 374 & $\mathrm{CHCl}_{3}$ \\
POC $(8,4)$ & 124 & 318 & $\mathrm{CHCl}_{3}$ \\
\hline
\end{tabular}

${ }^{*}$ Glass transition temperature, from DSC, $\mathrm{N}_{2}$ flow at $10^{\circ} \mathrm{C} / \mathrm{min}$ rate; $* * 5 \%$ weight loss temperature, from TGA, air flow at $20^{\circ} \mathrm{C} / \mathrm{min}$ rate. ${ }^{* * *}$ The polymer $\mathrm{POC}(6)$ has higher solubility in $\mathrm{DMF}$ than $\mathrm{CHCl}_{3}$.

solubility and higher $T_{g}\left(170^{\circ} \mathrm{C}\right)$, due to its shorter aliphatic chain portion. As an example, DSC trace of $\operatorname{POC}(8,4)$ is reported in Figure 2.

The X-ray diffraction pattern of virgin samples of POC, recorded at room temperature is reported in Figure 3. It shows a broad halo, confirming the amorphous nature of the polymers. 
<smiles>CC(C)(Br)CCCCCCC(C)(Br)Br</smiles><smiles>CCCCCCCn1c2ccccc2c2ccccc21</smiles>

Scheme 3: Synthesis of the polymers (POC).

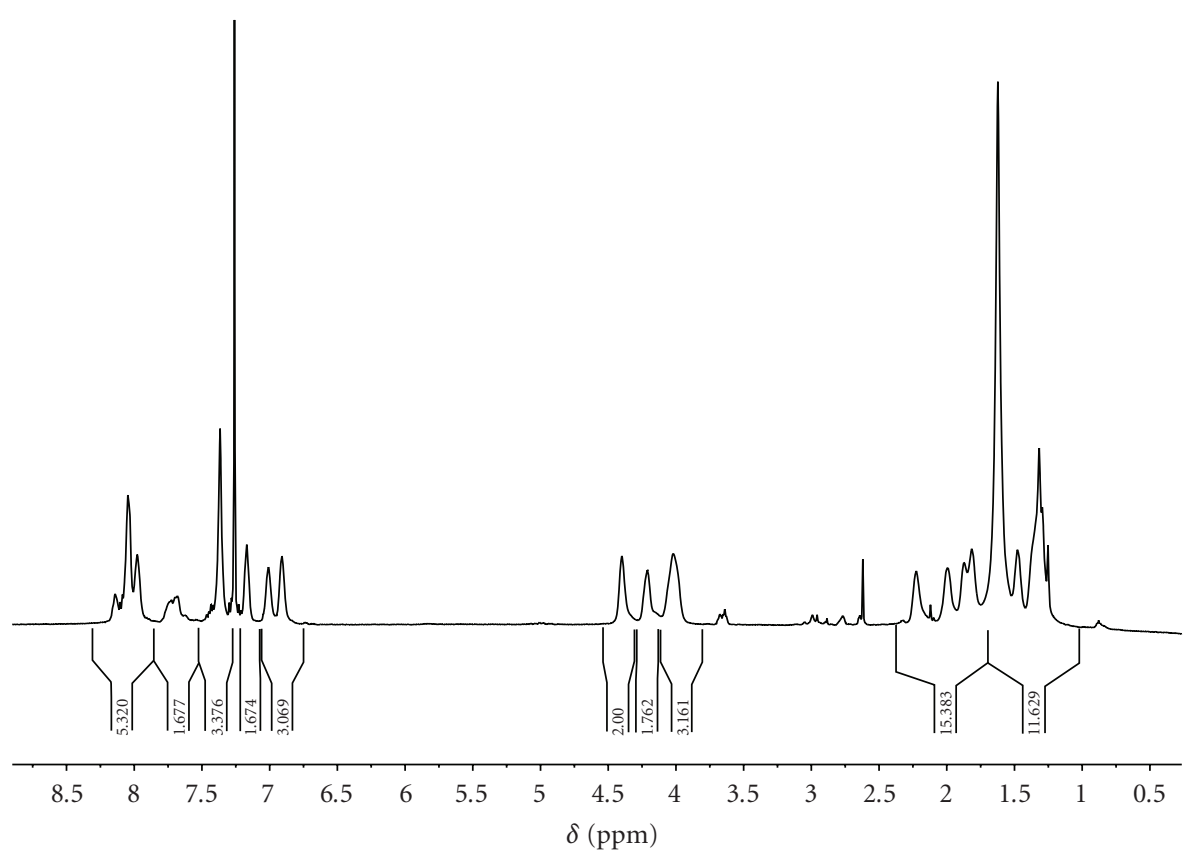

Figure $1:{ }^{1} \mathrm{H}$ NMR spectrum of $\mathrm{POC}(12,6)$ in deuterated chloroform solution.

In the thermogravimetric plots of POC, the degradation process, indicated with a single shoulder, is observed starting at a temperature of about $400^{\circ} \mathrm{C}$. This indicates stability of POC at temperatures lower than about $350^{\circ} \mathrm{C}$ (Table 1 ). As an example, thermogravimetric trace of $\operatorname{POC}(12,6)$ is reported in Figure 4.

POCs are easily soluble in a series of organic solvents; in particular, good-optical-quality films are obtained from chloroform or DMF (Table 1).
3.2. Optical and Photoluminescence Characterization. All POC polymers show similar absorption and emission spectra. As a representative example, UV and fluorescence spectra of $\operatorname{POC}(12,6)$ in chloroform solution are reported in Figure 5.

In analogy with our previous paper on low-molecularweight carbazole/oxadiazole compounds [18] and on oxadiazole-containing polymers [19-21], the carbazole moiety absorbs at lower wavelength (strong peak at $292 \mathrm{~nm}$ ) with 


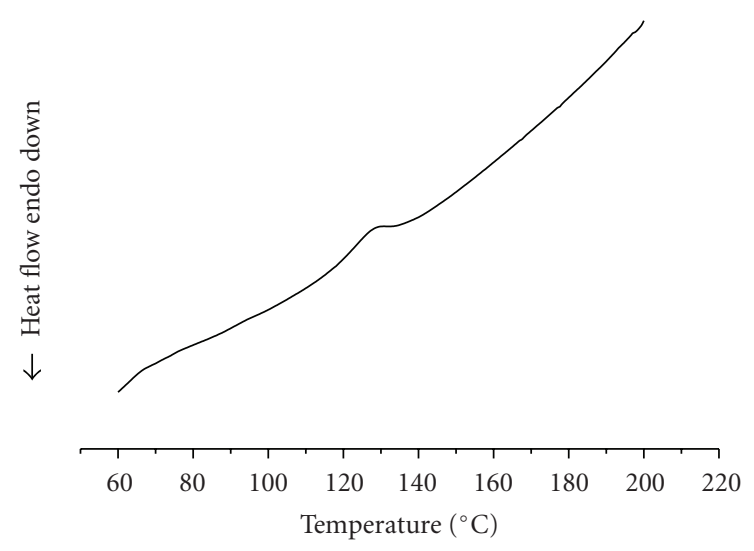

FIGURE 2: Calorimetric trace of virgin samples of $\operatorname{POC}(8,4)$, as obtained from the synthesis, first heating run.

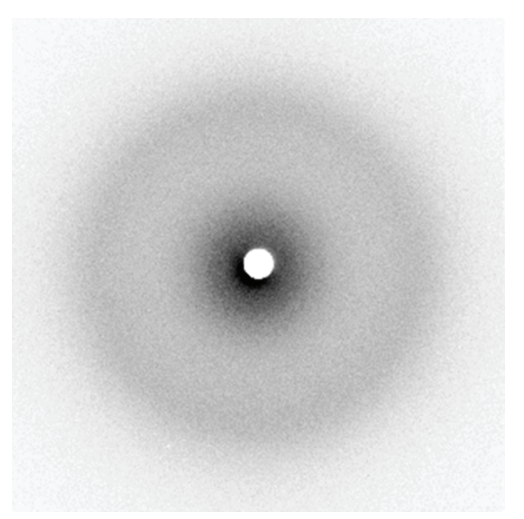

Figure 3: X-ray diffraction pattern of $\operatorname{POC}(12,6)$.

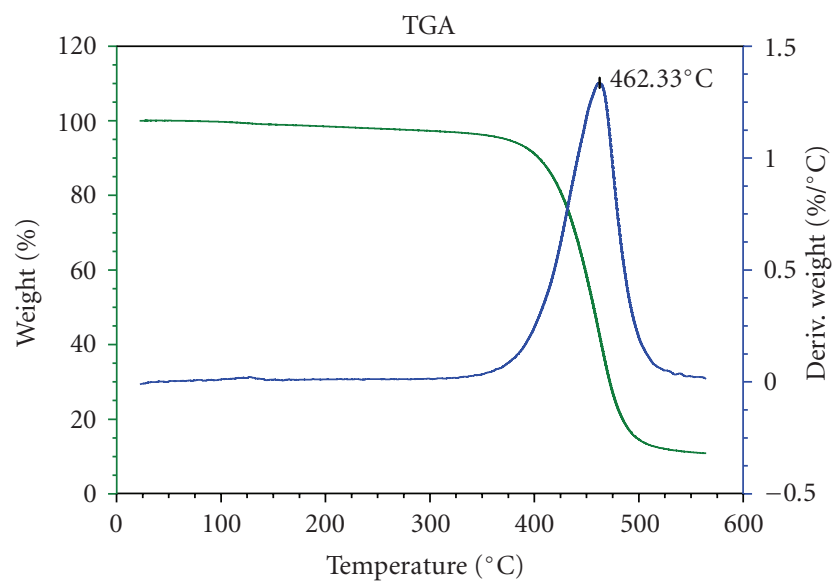

FIgURE 4: Thermogravimetric trace of $\operatorname{POC}(12,6)$.

respect to the oxadiazole unit (two strong and broad peaks at 322 and $345 \mathrm{~nm}$ ) and emits in the wavelength range (two strong peaks at 354 and $369 \mathrm{~nm}$ ) where the oxadiazole unit strongly absorbs. The result is that POCs show a strong blue emission, identical to that of analogue oxadiazole-containing polymers; in particular, the emission occurs at $407 \mathrm{~nm}$ (main peak, sharp) and at $460 \mathrm{~nm}$ (lower peak, broad band).

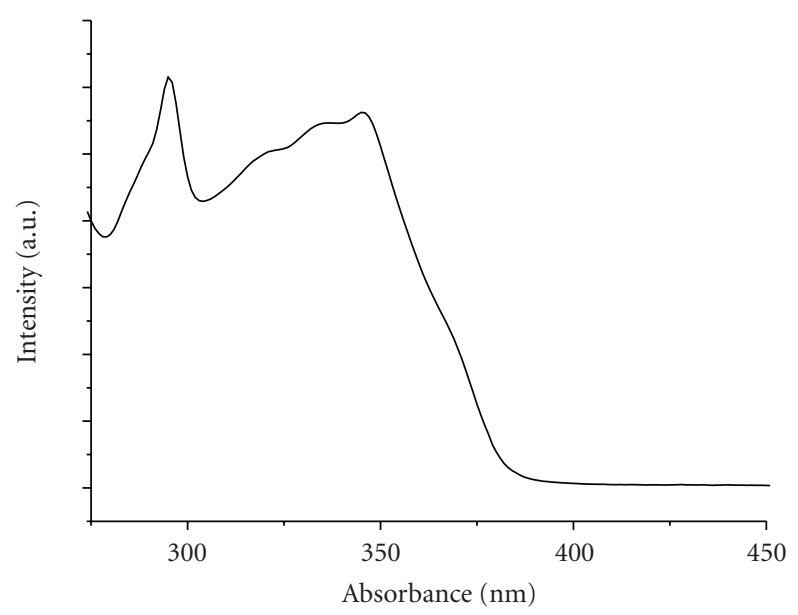

(a)

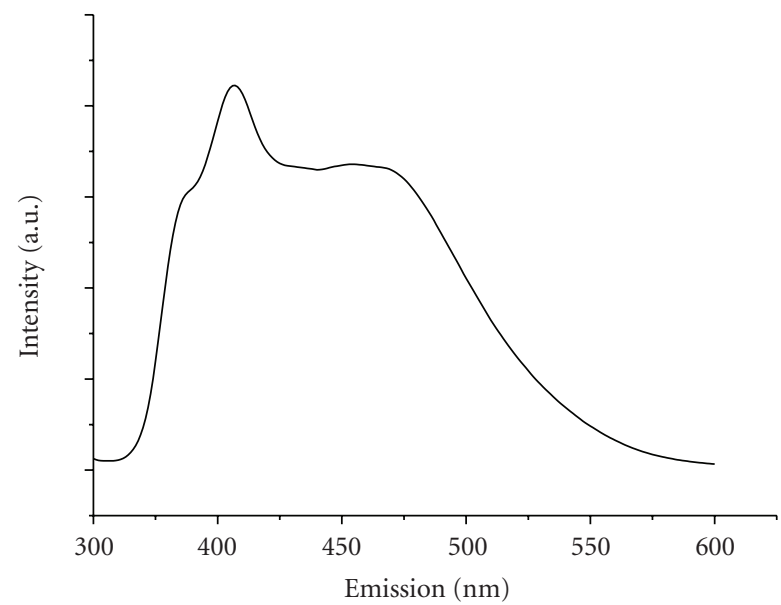

(b)

FIGURE 5: (a) Absorption and (b) photoluminescence of $\operatorname{POC}(12,6)$, irradiated at $345 \mathrm{~nm}$, in chloroform solution.

The good solubility in chlorinate solvents and DMF allows the preparation of films with homogeneous thickness by spin coating.

\section{Conclusions}

The new synthesized carbazole/oxadiazole-containing polymers (POCs) are blue photoluminescent materials. Taking advantage of the steric constraints due to the side insertion of carbazole unit to the oxadiazole moiety and to the insertion of flexible aliphatic segments in the main polymer chain, POCs are soluble in chlorinate organic solvents or DMF and they can be easily processed to homogenous films. The synthesized polymers show strong photoemission in the blue region of the visible spectrum. Taking advantage from these features, POC could be good candidate materials for the realization of single-layer organic LED.

\section{References}

[1] J. H. Burroughes, D. D. C. Bradley, A. R. Brown, et al., "Lightemitting diodes based on conjugated polymers," Nature, vol. 347, no. 6293, pp. 539-541, 1990. 
[2] A. B. Holmes, D. D. C. Bradley, A. R. Brown, et al., "Photoluminescence and electroluminescence in conjugated polymeric systems," Synthetic Metals, vol. 57, no. 1, pp. 40314040, 1993.

[3] M. Berggren, O. Inganas, G. Gustafsson, et al., "Light emitting diodes with variable colours from polymer blends," Nature, vol. 372, no. 6505, pp. 444-446, 1994.

[4] G. Grem, G. Leditzky, B. Ullrich, and G. Leising, "Realization of a blue-light-emitting device using poly(p-phenylene)," Advanced Materials, vol. 4, no. 1, pp. 36-37, 1992.

[5] C. Adachi, T. Tsutsui, and S. Saito, "Blue light-emitting organic electroluminescent devices," Applied Physics Letters, vol. 56, no. 9, pp. 799-801, 1990.

[6] J.-I. Lee, G. Klaerner, and R. D. Miller, "Oxidative stability and its effect on the photoluminescence of poly(fluorene) derivatives: end group effects," Chemistry of Materials, vol. 11, no. 4, pp. 1083-1088, 1999.

[7] Z. Peng and J. Zhang, "New oxadiazole-containing conjugated polymer for single-layer light-emitting diodes," Chemistry of Materials, vol. 11, no. 4, pp. 1138-1143, 1999.

[8] F.-C. Chen, G. He, and Y. Yang, "Triplet exciton confinement in phosphorescent polymer light-emitting diodes," Applied Physics Letters, vol. 82, no. 7, pp. 1006-1008, 2003.

[9] C. Adachi, R. C. Kwong, P. Djurovich, et al., "Endothermic energy transfer: a mechanism for generating very efficient high-energy phosphorescent emission in organic materials," Applied Physics Letters, vol. 79, no. 13, pp. 2082-2084, 2001.

[10] R. J. Holmes, S. R. Forrest, Y.-J. Tung, et al., "Blue organic electrophosphorescence using exothermic host-guest energy transfer," Applied Physics Letters, vol. 82, no. 15, pp. 24222424, 2003.

[11] H.-J. Su, F.-I. Wu, C.-F. Shu, Y.-L. Tung, Y. Chi, and G.-H. Lee, "Polyfluorene containing diphenylquinoline pendants and their applications in organic light emitting diodes," Journal of Polymer Science Part A, vol. 43, no. 4, pp. 859-869, 2005.

[12] Z. Liu, Y. Zhang, Y. Hu, et al., "Novel bipolar light-emitting copolymer containing triazole and triphenylamine moieties," Journal of Polymer Science Part A, vol. 40, no. 8, pp. 1122-1126, 2002.

[13] F.-I. Wu, P.-I. Shih, C.-F. Shu, Y.-L. Tung, and Y. Chi, "Highly efficient light-emitting diodes based on fluorene copolymer consisting of triarylamine units in the main chain and oxadiazole pendent groups," Macromolecules, vol. 38, no. 22, pp. 9028-9036, 2005.

[14] X.-C. Li, Y. Liu, M. S. Liu, and A. K.-Y. Jen, "Synthesis, properties, and application of new luminescent polymers with both hole and electron injection abilities for light-emitting devices," Chemistry of Materials, vol. 11, no. 6, pp. 1568-1575, 1999.

[15] Z. Peng, Z. Bao, and M. E. Galvin, "Polymers with bipolar carrier transport abilities for light emitting diodes," Chemistry of Materials, vol. 10, no. 8, pp. 2086-2090, 1998.

[16] J. Lu, A. R. Hlil, Y. Sun, et al., "Synthesis and characterization of a blue light emitting polymer containing both hole and electron transporting units," Chemistry of Materials, vol. 11, no. 9, pp. 2501-2507, 1999.

[17] M. B. Casu, P. Imperia, S. Schrader, B. Schulz, M. Jandke, and P. Strohriegl, "Valence electronic structure of oxadiazoles and quinoxalines model compounds," Synthetic Metals, vol. 121, no. 1-3, pp. 1397-1398, 2001.

[18] V. Bugatti, S. Concilio, P. Iannelli, et al., "Synthesis and characterization of new electroluminescent molecules containing carbazole and oxadiazole units," Synthetic Metals, vol. 156, no. 1, pp. 13-20, 2006.
[19] D. Acierno, E. Amendola, S. Bellone, et al., "Synthesis and luminescent properties of a new class of nematic oxadiazole containing poly-ethers for PLED," Journal of Non-Crystalline Solids, vol. 338-340, no. 1, pp. 278-282, 2004.

[20] D. Acierno, S. Concilio, A. Diodati, P. Iannelli, S. P. Piotto, and P. Scarfato, "Synthesis and liquid crystalline properties of low molecular mass compounds containing the 1,4-bis (5-phenyl1,3,4-oxadiazolyl) benzene unit," Liquid Crystals, vol. 29, no. 11, pp. 1383-1392, 2002.

[21] D. Acierno, E. Amendola, S. Bellone, et al., "Synthesis and characterization of a new class of nematic photoluminescent oxadiazole-containing polyethers," Macromolecules, vol. 36, no. 17, pp. 6410-6415, 2003. 

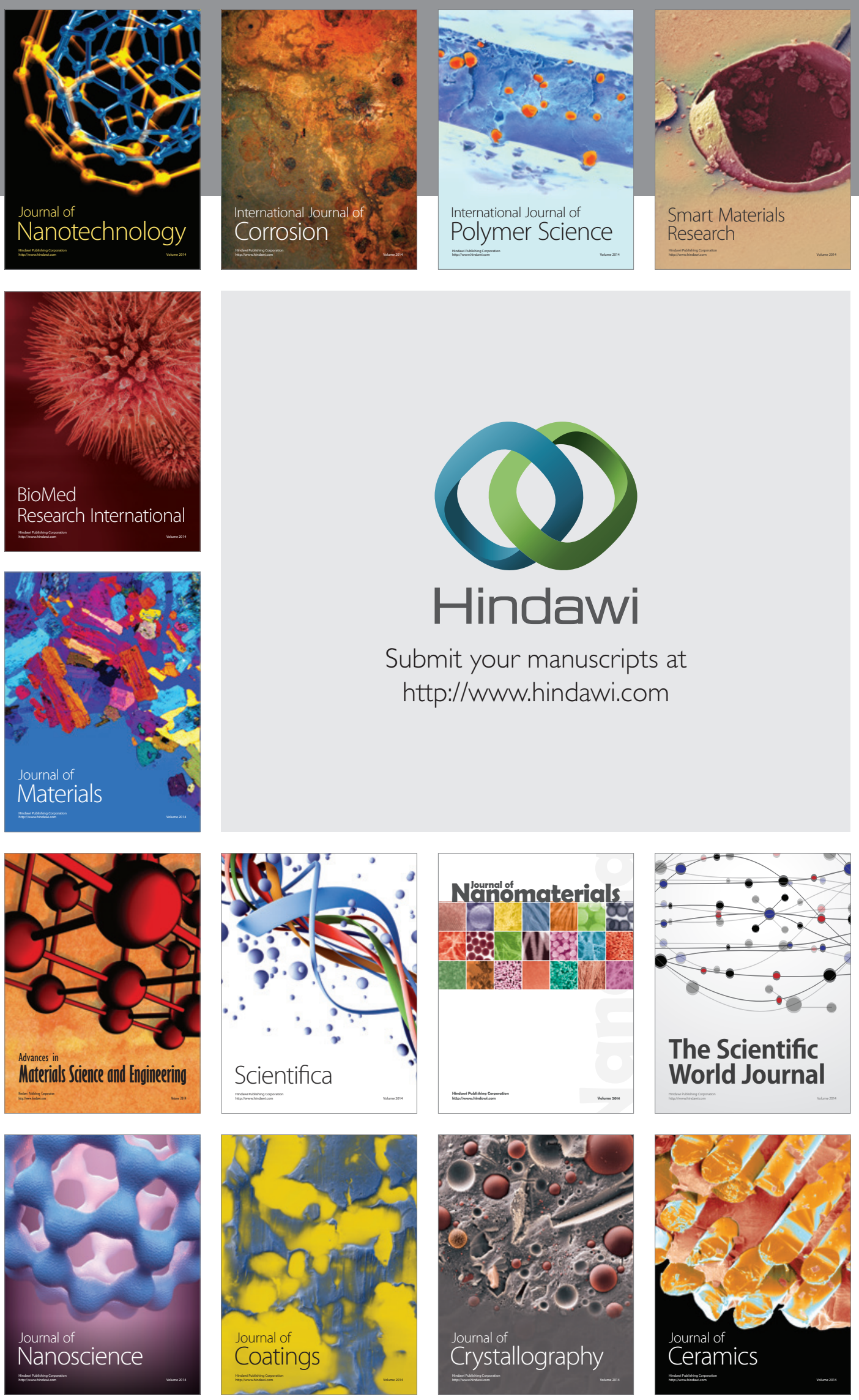

The Scientific World Journal

Submit your manuscripts at

http://www.hindawi.com

\section{World Journal}

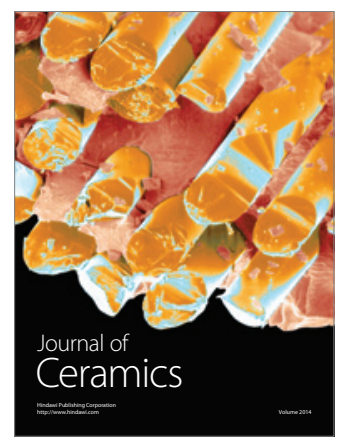

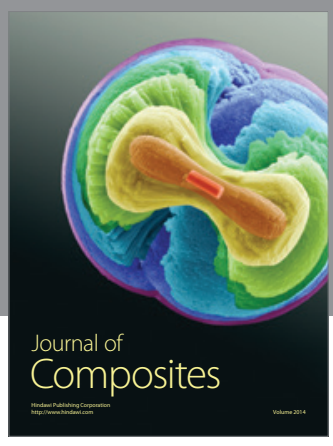
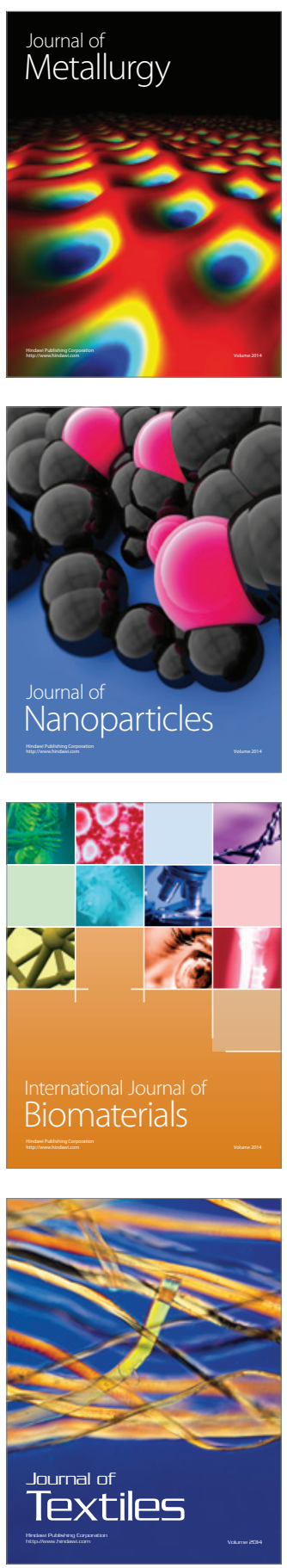